\title{
Chorioamnionitis induces changes in ovine pulmonary endogenous epithelial stem/progenitor cells in utero
}

Citation for published version (APA):

Widowski, H., Ophelders, D. R. M. G., van Leeuwen, A. J. C. N., Nikkels, P. G. J., Severens-Rijvers, C. A. H., LaPointe, V. L. S., Cleutjens, J. P. M., Hütten, M. C., Kemp, M. W., Payne, M. S., Saito, M., Usuda, H., Newnham, J. P., Jobe, A. H., Kramer, B. W., Delhaas, T., Wolfs, T. G. A. M., \& Reynaert, N. L. (2021). Chorioamnionitis induces changes in ovine pulmonary endogenous epithelial stem/progenitor cells in utero. Pediatric Research, 90(3), 549-558. https://doi.org/10.1038/s41390-020-01204-9

Document status and date:

Published: 01/09/2021

DOI:

10.1038/s41390-020-01204-9

Document Version:

Accepted author manuscript (Peer reviewed / editorial board version)

Document license:

CC BY-NC-ND

\section{Please check the document version of this publication:}

- A submitted manuscript is the version of the article upon submission and before peer-review. There can be important differences between the submitted version and the official published version of record.

People interested in the research are advised to contact the author for the final version of the publication, or visit the DOI to the publisher's website.

- The final author version and the galley proof are versions of the publication after peer review.

- The final published version features the final layout of the paper including the volume, issue and page numbers.

Link to publication

\footnotetext{
General rights rights.

- You may freely distribute the URL identifying the publication in the public portal. please follow below link for the End User Agreement:

www.umlib.nl/taverne-license

Take down policy

If you believe that this document breaches copyright please contact us at:

repository@maastrichtuniversity.nl

providing details and we will investigate your claim.
}

Copyright and moral rights for the publications made accessible in the public portal are retained by the authors and/or other copyright owners and it is a condition of accessing publications that users recognise and abide by the legal requirements associated with these

- Users may download and print one copy of any publication from the public portal for the purpose of private study or research.

- You may not further distribute the material or use it for any profit-making activity or commercial gain

If the publication is distributed under the terms of Article $25 \mathrm{fa}$ of the Dutch Copyright Act, indicated by the "Taverne" license above, 


\section{Chorioamnionitis induces changes in ovine pulmonary endogenous epithelial stem/progenitor cells in utero}

Cite this article as: Helene Widowski, Daan R. M. G. Ophelders, Anaïs J. C. N. van Leeuwen, Peter G. J. Nikkels, Carmen A. H. Severens-Rijvers, Vanessa L. S. LaPointe, Jack P. M. Cleutjens, Matthias C. Hütten, Matthew W. Kemp, Matthew S. Payne, Masatoshi Saito, Haruo Usuda, John P. Newnham, Alan H. Jobe, Boris W. Kramer, Tammo Delhaas, Tim G. A. M. Wolfs and Niki L. Reynaert, Chorioamnionitis induces changes in ovine pulmonary endogenous epithelial stem/progenitor cells in utero, Pediatric Research doi:10.1038/s41390-020-01204-9

This Author Accepted Manuscript is a PDF file of an unedited peer-reviewed manuscript that has been accepted for publication but has not been copyedited or corrected. The official version of record that is published in the journal is kept up to date and so may therefore differ from this version.

Terms of use and reuse: academic research for non-commercial purposes, see here for full terms. https://www.nature.com/authors/policies/license.html\#AAMtermsV1 


\section{AUTHOR ACCEPTED MANUSCRIPT}

Chorioamnionitis induces changes in ovine pulmonary endogenous epithelial

stem/progenitor cells in utero

Helene Widowski ${ }^{1,2,3}$, Daan R.M.G. Ophelders ${ }^{1,3}$, Anaïs J.C.N. van Leeuwen ${ }^{1}$, Peter G.J. Nikkels $^{4}$, Carmen A.H. Severens-Rijvers ${ }^{5,6}$, Vanessa L.S. LaPointe ${ }^{6}$, Jack P.M. Cleutjens ${ }^{5,7}$, Matthias C. Hütten ${ }^{8,9}$, Matthew W. Kemp ${ }^{10}$, Matthew S. Payne ${ }^{10}$, Masatoshi Saito ${ }^{10,11}$, Haruo Usuda $^{10,11}$, John P. Newnham ${ }^{10}$, Alan H. Jobe ${ }^{10,12}$, Boris W. Kramer ${ }^{1,3,13}$, Tammo Delhaas ${ }^{2,7}$, Tim G.A.M. Wolfs ${ }^{1,3}$, Niki L. Reynaert ${ }^{14,15^{*}}$

1 Department of Pediatrics, Maastricht University Medical Center, Maastricht, The Netherlands

2 Department of BioMedical Engineering, Maastricht University Medical Center, Maastricht, The Netherlands

3 GROW School for Oncology and Developmental Biology, Maastricht University Medical Center, Maastricht, The Netherlands

4 Department of Pathology, University Medical Center Utrecht, Utrecht, The Netherlands

5 Department of Pathology, Maastricht University Medical Center, Maastricht, The Netherlands

6 Department of Cell Biology-Inspired Tissue Engineering, MERLN Institute for Technology-Inspired Regenerative Medicine, Maastricht University, Maastricht, The Netherlands

7 CARIM School for Cardiovascular Diseases, Maastricht University Medical Center, Maastricht, The Netherlands

8 Neonatology, Pediatrics Department, Faculty of Health, Medicine and Life Sciences, Maastricht University Medical Center, Maastricht, The Netherlands

9 University Children's Hospital Würzburg, University of Würzburg, Würzburg, Germany 


\section{AUTHOR ACCEPTED MANUSCRIPT}

Division of Obstetrics and Gynecology, The University of Western Australia, Crawley, WA, Australia

11 Tohoku University Centre for Perinatal and Neonatal Medicine, Tohoku University Hospital, Sendai, Japan

12 Perinatal Institute Cincinnati Children's Hospital Medical Centre, Cincinnati, OH

13 School for Mental Health and Neuroscience, Maastricht University, Maastricht, The Netherlands

Department of Respiratory Medicine, Maastricht University, Maastricht, The Netherlands NUTRIM School of Nutrition and Translational Research in Metabolism, Maastricht University Medical Center, Maastricht, The Netherlands

Address for reprint requests and other correspondence:

Niki L. Reynaert, Department of Respiratory Medicine, Maastricht University, Maastricht, the Netherlands

(email: n.reynaert@maastrichtuniversity.nl)

Address: PO Box 616, 6200MD Maastricht, the Netherlands

Phone: +31 433882270

Fax: $+3104303875051 / 7087$

\section{Author contributions}

H.W., T.G.W. and N.L.R. contributed to the conception and design of the research, and H.W., A.J.L., M.W.K., M.S.P., A.H.J., M.S., H.U., J.P.N. and B.W.K. participated in conduction of experiments, acquirement and analysis of data. H.W., D.R.O., P.G.N., C.A.S., V.L.L., B.W.K., T.D., T.G.W. and N.L.R. drafted, edited and revised the manuscript. H.W., D.R.O., 


\section{AUTHOR ACCEPTED MANUSCRIPT}

A.J.L., P.G.N., C.A.S., V.L.L., J.P.C., M.C.H., M.W.K., M.S.P., A.H.J., M.S., H.U., J.P.N.,

B.W.K., T.D., T.G.W. and N.L.R. approved final version of manuscript.

No patient consent was required for this study.

Statement of financial support:

This work was supported by a National Institutes of Health (Bethesda, MD, USA) grant (HD 57869) and by the Dutch Lung Foundation (Longfonds, Grant no. 6.1.16.088 T.G.W., N.L.R., P.G.N.).

Competing interests: The authors declare no competing interests.

Category of study: Basic Science Article

Impact

- In this study prenatal inflammation improved lung function at the expense of stem/progenitor alterations that potentially disrupt normal lung development, thereby predisposing to adverse postnatal outcomes.

- Importantly, we demonstrate that these essential alterations can already be initiated before birth. So far stem/progenitor dysfunction has only be shown postnatally.

- This study indicates that clinical protocols to target the consequences of perinatal inflammatory stress for the immature lungs should be initiated as early as possible, and ideally in utero. Within this context, our data suggest that interventions, which promote function or repair of endogenous stem cells in the lungs hold great promise. 


\section{AUTHOR ACCEPTED MANUSCRIPT}

\section{Abstract}

Background: Chorioamnionitis, an intrauterine infection of the placenta and fetal membranes, is a common risk factor for adverse pulmonary outcomes in premature infants including BPD, which is characterized by an arrest in alveolar development. As endogenous epithelial stem/progenitor cells are crucial for organogenesis and tissue repair, we examined whether intrauterine inflammation negatively affects these essential progenitor pools.

Methods: In an ovine chorioamnionitis model, fetuses were intra-amniotically exposed to LPS, $2 \mathrm{~d}$ or $7 \mathrm{~d}$ (acute inflammation) before preterm delivery at $125 \mathrm{~d}$ of gestation, or to intraamniotic Ureaplasma parvum for $42 \mathrm{~d}$ (chronic inflammation). Lung function, pulmonary endogenous epithelial stem/progenitor pools and downstream functional markers were studied.

Results: Lung function was improved in 7d LPS and 42d Ureaplasma groups. However, intrauterine inflammation caused a loss of P63+ basal cells in proximal airways and reduced SOX-9 expression and TTF-1+ Club cells in distal airways. Attenuated type- 2 cell numbers were associated with lower proliferation and reduced type-1 cell marker Aqp5 expression, indicative for impaired progenitor function. Chronic Ureaplasma infection only affected distal airways, whereas acute inflammation affected stem/progenitor populations throughout the lungs.

Conclusion: Acute and chronic prenatal inflammation improve lung function at the expense of stem/progenitor alterations that potentially disrupt normal lung development, thereby predisposing to adverse postnatal outcomes. 


\section{AUTHOR ACCEPTED MANUSCRIPT}

\section{Introduction}

Chorioamnionitis, associated with intrauterine infection, is a common risk factor for preterm birth. It is classified as either clinical or histologic chorioamnionitis. Clinical chorioamnionitis is defined by maternal fever, uterine tenderness and maternal systemic inflammation, whereas histologic chorioamnionitis is silent and determined by an intrauterine infection and inflammation, which is caused by a microbial invasion into the placenta, fetal membranes, and amniotic fluid $(1,2)$. Ureaplasma (UP) species are the most frequently isolated microorganisms from clinical specimens of chorioamnionitis (3). Chorioamnionitis can elicit a systemic immune response in the developing fetus and is therefore a common risk factor for adverse pulmonary outcomes in premature infants (4). Preterm birth along with intrauterine inflammation are strongly associated with the most frequent and severe disorder of the premature lungs, known as BPD, which is characterized by an arrest in the alveolarization process and a reduced vascular network $(5,6)$.

Endogenous stem/progenitor cells are crucial drivers of organogenesis and play a pivotal role in lung growth and development, but also in the repair of injured lung tissue (7). Assuming that the fragile lungs of preterm infants can neither resume healthy growth nor repair themselves after perinatal insults, there is increasing attention for impaired endogenous pulmonary stem/progenitor cells and their emerging role in (preterm) adverse pulmonary outcomes that frequently result in life-long respiratory burden (8). Several groups have provided evidence to support the concept that dysfunctional endogenous pulmonary stem/progenitor cells or altered stem/progenitor cell pools contribute to neonatal morbidities (9-11). These groups reported developmental changes caused by postnatal pro-inflammatory insults, including ventilation and hyperoxia. Interestingly, evidence exists that the first 


\section{AUTHOR ACCEPTED MANUSCRIPT}

negative impact on pulmonary development actually already occurs in utero, in the presence of chorioamnionitis $(12,13)$. Therefore, we hypothesize that alterations in essential stem/progenitor cell populations are induced prenatally by intrauterine inflammation and that these changes might contribute to adverse lung outcomes postnatally and further predispose the preterm infant to long-term pulmonary impairment. To address this question, a wellestablished ovine model for intrauterine inflammation was used. Preterm ovine fetuses were exposed 42 days (d) intra-amniotically to UP species, or $2 \mathrm{~d}$ or $7 \mathrm{~d}$ to Escherichia coli-derived LPS to mimic chronic infection versus an acute inflammatory situation (14). Two time points were chosen for LPS exposure, as previous studies reported inflammatory and structural changes in the developing lungs $2 \mathrm{~d}$ and $7 \mathrm{~d}$ after LPS exposure, respectively (12). This study allows the investigation of chronic and acute inflammatory triggers and the impact of timing and duration of exposure in a model for the developing lungs of premature babies. 


\section{AUTHOR ACCEPTED MANUSCRIPT}

\section{Material and Methods}

\section{$\underline{\text { Animal model and sampling protocol }}$}

Experimental animal procedures were approved by the animal ethics committee of the University of Western Australia (Perth, Australia) and published previously (14). Briefly, 28 time-mated Merino ewes of both sexes were randomly assigned to an experimental group (Supplemental Fig. S1, online). Ewes received an ultra-sound guided intra-amniotic injection of live UP serovar 3 strain HPA5 ( $2 \times 10^{5}$ color-changing units CCU), $42 \mathrm{~d}$ before preterm delivery at $125 \mathrm{~d}$ of GA (term=150d). UP was prepared from stock cultures, diluted in sterile culture medium and diluted to 1:100 in sterile saline to reduce inflammatory effects. LPS groups were exposed to an ultra-sound guided intra-amniotic injection of 10mg LPS (Escherichia coli 055:B5; Sigma-Aldrich, St. Louis, MO) either 2d or 7d prior to preterm delivery. Control groups received an equivalent injection with saline, which was also used to dissolve LPS. The ewe was euthanized, and the fetus was surgically delivered and euthanized. Right lower lobe lung tissue (RLL) was snap frozen, and the right upper lobe (RUL) was inflation-fixed at $30 \mathrm{~cm} \mathrm{H}_{2} \mathrm{O}$ in $10 \%$ buffered formalin for $24 \mathrm{~h}$.

\section{$\underline{\text { Ureaplasma titers }}$}

Amniotic fluid samples of the UP group, obtained on the day of sacrifice, were positive for UP, whereas LPS treated and control animals did not show any microbial growth. Plasma samples of all experimental groups were negative for UP (14).

\section{$\underline{\text { Pulmonary pressure-volume curve }}$}




\section{AUTHOR ACCEPTED MANUSCRIPT}

Pulmonary pressure-volume measurements were performed by opening the thorax and inserting an endotracheal tube in the trachea. Lungs were inflated to a maximum pressure of $40 \mathrm{~cm} \mathrm{H}_{2} \mathrm{O}$ and volumes of lung deflation were recorded at pre-specified pressures and normalized to body weight (15).

\section{$\underline{\text { Histology and immunohistochemistry }}$}

Paraffin-embedded RUL sections $(4 \mu \mathrm{m})$ were stained histochemically with hematoxylin and eosin (H\&E) for lung structure visualization and immunohistochemically for neutrophils with myeloperoxidase (MPO, 1:500, A-0398, Dako, Santa Clara, CA) and with CD45 for immune cells (1:500, MCA2220GA, Biorad, Hercules, CA). Endogenous pulmonary stem/progenitor cell markers comprised tumor protein 63 (P63, 1:8000, ab124762, Abcam) indicative for basal cells of the proximal airways, Keratin-14 (KRT-14, 1:1000, 905301, Biolegend, San Diego, CA) to detect differentiation of basal cells, thyroid transcription factor-1 (TTF-1, 1:8000, WRAB-1231, Seven Hills Bioreagents, Cincinnati, OH) to visualize Club cells in the distal airways and alveolar type 2 cells (AEC2) in alveoli (16). Additionally, proliferation marker Ki67 (1:1000, 15580, Abcam, Cambridge, UK) and apoptosis marker cleaved caspase-3 (Casp-3, 1:200, 9661S, Cell signaling, Danvers, MA) were included. MPO and TTF-1 protocols were modified for this study. Briefly, after deparaffinization and rehydration, endogenous peroxidase activity was quenched by incubating sections in $0.3 \% \mathrm{H}_{2} \mathrm{O}_{2}$. Antigen retrieval for CD45, TTF-1, Ki67 and Casp-3 was performed by boiling sections in citrate buffer ( $\mathrm{pH}$ 6.0), while KRT-14 slides were incubated in sodium citrate (pH 6.0). Non-specific binding of antibodies was prevented with 5\% BSA (TTF-1, KRT-14, Ki67, Casp-3), 2\% (P63), 4\% (CD45) and 10\% (MPO) normal goat serum. Primary antibodies were incubated over night at $4{ }^{\circ} \mathrm{C}$ (for MPO $1 \mathrm{~h}$ at room temperature). Subsequently, secondary antibodies (1:200), biotin-labeled Swine-anti-Rabbit (TTF-1, KRT-14, Ki67, Casp-3, E0353, Dako), 


\section{AUTHOR ACCEPTED MANUSCRIPT}

biotin-labeled Goat-anti-Mouse (P63, CD45, E0433, Dako), or Goat-anti-Rabbit HRP (MPO, 111-035-045, Bio-connect) were incubated for $1 \mathrm{~h}$ (30min for MPO). Augmentation of the antibody-specific signal was achieved with a Vectastain ABC Elite kit (PK-6100, Bioconnect) (P63, KRT-14, TTF-1, Ki67, Casp-3). For visualization of MPO, slides were stained with an AEC chromogen-substrate staining. For CD45 and Casp-3 a diaminobenzidine staining was used, while P63, TTF-1 and KRT-14 staining required an incubation in Nickelenhanced diaminobenzidine. Counterstaining with $0.1 \%$ Nuclear Fast Red was performed for TTF-1 (Club cells), or with haematoxylin for CD45, MPO and Casp-3.

Isotype controls (IgG isotype control, CABT-B8473, Creative diagnostics) were used for P63 and TTF-1 and stained according to the identical protocols. The results can be seen online in Supplemental Fig. S2.

\section{$\underline{\text { Immunohistochemical analyses }}$}

Analysis of immunohistochemical stainings was performed with a light microscope (Leica DM2000, Rijswijk, the Netherlands) and the Leica Application Suite 3.7.0 software (Leica Microsystem, Wetzlar, Germany).

Per animal one section of the RUL was investigated by two blinded observers. Analysis of stainings was performed according to the location of the markers. For P63 and KRT-14, 5 randomly chosen cross-sectional cut proximal airways were analysed per section, while 5 randomly chosen distal airways were used for TTF-1 to analyze Club cells. TTF-1-positive (+) AEC2 were quantified in 5 high power fields (HPF) in alveoli, excluding crossing septa, vessels and bronchioles. Regions of interest were chosen randomly throughout the section. Proximal and distal airways were identified according to the presence versus absence of cartilage plates and mucosal glands, respectively (17). According to these airway characteristics, we determined a cut-off value of $200 \mu \mathrm{m}$ bronchial diameter in ovine fetal 


\section{AUTHOR ACCEPTED MANUSCRIPT}

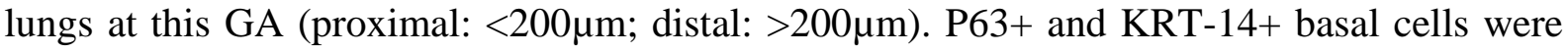
enumerated with a standard threshold to detect positive cells with Leica QWin Pro V3.5.1 software (Leica Microsystem), restricted to the bronchial epithelium. TTF-1 stained Club cells were counted in distal airways and terminal bronchioles. A magnification of 200x was used for P63 and KRT-14 analyses. TTF-1+ AEC2 were quantified with a similar standard threshold at 100x magnification.

Additionally, for P63, KRT-14 and TTF-1+ Club cell analyses the perimeter of the bronchial ring/branch was measured with ImageJ software (ImageJ 1.52i software, Bethesda, MD, USA) to determine the number of positive cells per millimeter of bronchial and bronchiolar lining. For AEC2 analysis the surface area of the HPFs was determined with a different Qwin software algorithm and positive cells were presented per square millimeter.

In alveoli further analyses were performed on Ki67, MPO and CD45: At a magnification of 200x 5 random pictures were taken of the alveoli. The alveolar compartment comprised the alveolar walls, alveolar airspaces and perivascular space for the quantification of MPO and CD45, while Ki67 was analyzed only in alveolar walls. The surface area was determined with a Qwin software algorithm to display results as positive cells per square millimeter.

\section{$\underline{\text { Real-time PCR }}$}

RNA was extracted from snap-frozen RLL using Trizol (15596, Invitrogen, Waltham, MA)/chloroform (12). Genomic DNA was eliminated (QIAmp DNA Mini Kit (51306, Qiagen, Hilden, Germany)), followed by RT-PCR into cDNA with the SensiFast ${ }^{\mathrm{TM}}$ cDNA Synthesis Kit (BIO-65053, Bio-line, London, UK). Real-time qPCR was performed in duplicate, with the SensiMix ${ }^{\mathrm{TM}}$ SYBR Hi-Rox Kit (QT605, GC Bioline), using the LightCycler-480 Instrument (Roche Applied Science, Basel, Switzerland). Ovine specific primers were designed based on genome sequences of Ovis aries (Table 1), and partially 


\section{AUTHOR ACCEPTED MANUSCRIPT}

previously published (13). Results were normalized to the Geomean of the housekeeping genes ribosomal protein S15 (RPS15), Glyceraldehyde-3-phosphatedehydrogenase (GAPDH) and Human-14-3-3 protein zeta/delta (YWHAZ). Relative changes in expression were determined over control values. Because lung tissue for mRNA analysis was not available from all animals, group sizes may differ by 1-2 animals from immunohistochemical stainings.

\section{$\underline{\text { Statistics }}$}

All results are presented as means and with a CI of $95 \%$ or a SEM, with a significance level of $p<0.05$. Actual $p$ values between 0.05 and 0.1 were reported when interpreted as biologically relevant, as described previously (15). Non-parametric ANOVA with subsequent post-hoc analysis, using Dunn's Multiple Comparison Test, was performed to determine the statistical significance of the difference between the experimental groups (15).

Statistical analysis for the pressure volume curve was obtained for the entire expiratory slope and for each pressure point in a point-by-point manner. 


\section{Results}

Chronic and acute inflammatory stimuli elicited an inflammatory response in the premature lungs

To assess pulmonary inflammation, cytokine and chemokine levels were measured, and immune cells enumerated in alveoli. An increase of IL-6, IL-8, CCL2, CCR2, IL-1 $\beta$ and TNF- $\alpha$ (Fig. 1A-D, IL-1 $\beta$ and TNF- $\alpha$ data not shown) mRNA levels was determined in $2 d$ LPS-exposed animals, compared to controls (IL-6: SAL vs. 2d LPS, $p=0.0025$; IL-8: SAL vs. 2d LPS, $p=0.0007$; CCL2: SAL vs. 2d LPS, $p=<0.0001$; CCR2: SAL vs. 2d LPS, $p=<0.0001$ ). These cytokine/chemokine levels were normalized in 7d LPS-exposed animals, apart from CCR2 mRNA levels which remained elevated (SAL vs. 7d LPS, $p=0.0079$ ). UP did not affect mRNA levels of these cytokines/chemokines in the lung tissue $42 \mathrm{~d}$ after infection. In the $2 \mathrm{~d}$ LPS group a marked infiltration of macrophages was visible in H\&E sections (Supplemental Fig. S3, online). Significantly increased numbers of CD45+ immune cells (Fig. 1E, SAL vs. 2d LPS, $p=0.0204$ ), and neutrophils were measured in $2 \mathrm{~d}$ and 7d LPS animals (Fig. 1F, SAL vs. 2d LPS, $p=0.01$; SAL vs. $7 \mathrm{~d}$ LPS, $p=0.0004$ ). Neutrophils tended to be also increased in 42d UP-infected animals (SAL vs. 42d UP, $p=0.0545$ ).

No morphological changes in alveoli or bronchi were determined on histological sections that could influence the analysis of immunohistochemical stainings.

\section{Acute inflammation reduced the $\mathbf{P 6 3}+$ basal cell population in the proximal airways}




\section{AUTHOR ACCEPTED MANUSCRIPT}

Although the development of the proximal airways is largely completed at the time of the inflammatory hits, proximal progenitor cells are exposed to the inflammatory environment and have been shown in adult diseases to contribute to distal lung repair (18). The transcription factor SOX-2 is essential in early and late lung development, driving the branching of the respiratory tree, and regulating proximal airway progenitor cell proliferation and differentiation (19). To assess the impact of acute and chronic inflammation on proximal airway progenitors, SOX-2 expression was assessed. SOX-2 mRNA levels were unchanged both after chronic UP exposure and after $2 \mathrm{~d}$ and $7 \mathrm{~d}$ acute LPS exposure (Fig. 2A).

We examined the main proximal progenitor cell population, namely $\mathrm{P} 63+$ basal cells. Interestingly, P63 expressing cells were significantly decreased in the $7 d$ LPS group compared to controls (Fig. 2B, D-G, SAL vs. 7d LPS, $p=0.0182$ ).

KRT-14 is a differentiation marker for basal cells, and was additionally assessed in proximal airways, to determine consequences of reduced P63+ basal cell numbers (Fig. 2C). KRT-14 analysis revealed no changes in the number of KRT-14+ cells in either treatment group, indicating that intrauterine inflammation had no effect on KRT-14-related basal cell differentiation.

\section{Chronic and acute intrauterine inflammation caused a loss of Club cells and AEC2}

The transcription factor SOX-9 has a crucial role in distal airway development by controlling distal progenitor cell proliferation and differentiation (19). Therefore, SOX-9 expression was assessed to receive insight into the effects of acute and chronic inflammation on the distal lung development. SOX-9 mRNA levels significantly dropped in 42d UP-infected animals, and in 7d LPS-exposed animals (Fig. 3A, SAL vs. 42d UP, $p=0.031$; SAL vs. 7d LPS, $p=0.0421$ ). These results prompted us to study the distal lung progenitors, including surfactant producing Club cells in the distal bronchioles and AEC2 in the alveoli. 


\section{AUTHOR ACCEPTED MANUSCRIPT}

TTF-1+ cells in the distal bronchioles were decreased, indicating diminished numbers of the

Club cell population in $2 \mathrm{~d}$ and $7 \mathrm{~d}$ LPS groups (Fig. 3B-F, SAL vs. $2 \mathrm{~d}$ LPS, $p=0.0022$; SAL vs. 7d LPS, $p=0.0026)$. Even though not significant, a decrease in Club cell population was also found in 42d UP-infected animals (SAL vs. 42d UP, $p=0.0514$ ).

A similar pattern was found in the alveoli, where the number of TTF-1 expressing AEC2 overall was decreased (Fig. 4A, E-H). In addition, a significant decrease in AEC2 pool with progenitor potential was also observed in UP-infected animals (SAL vs. 42d UP, $p=0.0149$ ).

\section{Proliferative potential and Aqp5 mRNA levels were reduced after exposure to chronic and acute inflammatory triggers}

The lower number of stem/progenitor cells could be the result of less proliferation or increased cell death. We therefore assessed proliferation (Ki67, Fig. 4C) and apoptosis (Casp3 ) in the proximal airways and developing alveoli. Additionally, we analyzed TGF- $\beta$ expression, an important growth factor for lung development (Fig. 4B). A significant decrease in TGF- $\beta$ mRNA levels (Fig. 4B) and a reduced number of Ki67+ cells in alveoli (Fig. 4C) were detected in chronically infected animals and in 7d LPS animals (TGF- $\beta$ : SAL vs. 42d UP, $p=0.0027$; SAL vs. 7d LPS, $p=0.0290$; Ki67: SAL vs. 42d UP, $p=0.0397$; SAL vs. 7d LPS, $p=0.0125$ ). A similar pattern for Ki67 was measured in the proximal airways (data not shown). No difference in Casp-3+ cells was found in all treatment groups compared to controls (data not shown).

As previous results point towards reduced AEC2 populations, associated with lower proliferation, we further looked into their progenitor function by assessing differentiation towards AEC1. AEC1 were examined using the expression of Aqp5 as a marker for this cell type (Fig. 4D). Interestingly, Aqp5 expression in the preterm lungs emerges around 120d GA and increases proportional to increasing GA (Supplemental Fig. S4, online). Aqp5 expression 


\section{AUTHOR ACCEPTED MANUSCRIPT}

was reduced after chronic and acute inflammation, with the 7d LPS group being statistically significant (Fig. 4D, SAL vs. 7d LPS, $p=0.0331$ ).

\section{Acute LPS exposure enhanced surfactant mRNA levels in preterm ovine lungs}

Decreased proliferation and differentiation of a reduced AEC2 population prompted us to investigate the synthesis of surfactant proteins A-D, since AEC2 are the major producer of surfactant proteins. While SP-B and -C are major components in keeping the surface tension low, SP-A and -D have a role in the structural organization of surfactant and its homeostasis, respectively, and are additionally responsible for pathogen recognition.

Chronic UP inflammation did not alter mRNA levels of any of the surfactant proteins. However, SP-A mRNA levels increased significantly during $2 \mathrm{~d}$ and $7 \mathrm{~d}$ acute LPS inflammation (Fig. 5A, SAL vs. 2d LPS, $p=0.0095$; SAL vs. 7d LPS, $p=0.0152$ ).

mRNA levels of SP-D were increased in the 2d LPS group, and markedly elevated in 7d LPSexposed animals, compared to controls (Fig. 5D, SAL vs. 2d LPS, $p=0.0602$; SAL vs. 7d LPS, $p=0.0033)$.

SP-B mRNA levels were increased in the 2d LPS group (Fig. 5B), whereas SP-C mRNA levels were elevated at 7d after LPS exposure (Fig. 5C, SAL vs. 7d LPS, $p=0.093$ ).

\section{Lung gas volumes were increased after chronic and acute inflammation}

As we determined increased surfactant mRNA levels after acute inflammation, we further assessed lung gas volumes (Fig. 5E). Chronic UP infection led to significantly higher lung gas volumes, compared to controls (SAL vs. 42d UP, $p=0.0143$ ). Additionally, lung gas volumes were higher in the 7d LPS group (SAL vs. 7d LPS, $p=0.0001$ ). 


\section{Discussion}

Accumulating evidence suggest that crucial events occurring perinatally, can have a tremendous impact on the later health status of an adult (20). From chronic obstructive pulmonary disease (COPD) cohort studies, evidence was provided that patients with negative early life experiences, including low birth weight, prematurity and BPD, were predisposed to develop COPD later in life (21). More importantly, Um-Bergström showed long-term lung function impairment in adults with a history of BPD, in comparison with childhood asthma and preterm infants without (pulmonary) complications (22). The underlying causes for such prolonged lung function impairment, resulting from adverse lung development, are poorly understood.

Recently, the idea of altered stem/progenitor cell pools as potential contributor to aberrant development of the lungs and to the predisposition to BPD has been suggested (8). This concept emerged among others from clinical studies, reporting lower numbers of endogenous circulating endothelial progenitor populations that were associated with the development of BPD preterm infants (23).

Our study, in which we show that intrauterine inflammation negatively impacts populations of epithelial stem/progenitor cells by affecting their function and numbers, supports and extends this concept. Importantly, we demonstrate that such essential alterations can be already initiated before birth and that the type of inflammatory trigger, timing and duration of the exposure influences the dimensions of the effects. For instance, the impact of chronic 


\section{AUTHOR ACCEPTED MANUSCRIPT}

infection on stem/progenitor populations is detected primarily in the distal airways and alveoli, while the effects of an acute insult are more pronounced and affect stem/progenitor populations throughout the entire lung. Besides the use of a living microorganism versus a microbial toxin, the GA of the ovine fetuses, along with the developmental stage of the lungs at the time of inflammation, might be responsible for the varying susceptibility of stem/progenitor cells towards the inflammatory trigger. In the $3^{\text {rd }}$ trimester of gestation and in the alveolar stage of lung development (ovine fetuses at 125d GA) (24), proximal airways are substantially developed, whereas bronchioles and alveoli are still expanding. Therefore, induction of potential injury within the proximal part of the lungs in the $2^{\text {nd }}$ trimester might be repaired within the $42 \mathrm{~d}$ post UP infection.

Another explanation for lower susceptibility in the proximal airways might be the anatomical and histological differences with the distal airways. The pseudostratified columnar epithelium in the proximal airways overlays the basal cell layer and therefore no direct contact between basal cells and the airway lumen, where potential pathogens reside, can occur (25). Additionally, various types of tight junctions and adhesion molecules determine the integrity of the epithelial layer and its barrier function (26). In contrast, the distal airways are covered by a cuboidal layer of epithelial cells, exposing Club cells directly to inflammatory triggers.

There are several mechanisms that potentially underlie the apparent loss of stem/progenitor cells following intrauterine inflammation: lower population numbers most commonly result from an arrest in cell proliferation or increased cell death. According to the current data, a reduced proliferative capacity was observed for proximal (data not shown) and distal airways, indicative for diminished stem/progenitor function, whereas no increase in cell death was found. Furthermore, as pulmonary stem/progenitor cells are located in and controlled by specific stem cell niches, disturbances in these niches might also influence the residing stem/progenitor cells (27). For instance, Kuypers et al. found aberrant Wingless-Int (Wnt) and 


\section{AUTHOR ACCEPTED MANUSCRIPT}

Sonic hedgehog signaling in chorioamnionitis-exposed preterm lamb lungs (13), indicating that essential developmental processes are affected by intrauterine inflammation and potentially contribute to changes of progenitor cell function. The disturbed Wnt signaling and reduced stem/progenitor cell pools occurring prenatally, are also suggested to be involved in the onset and progression of chronic lung diseases later in life (28). In line, we report developmental changes in SOX-9 expression, which is reduced after chronic and acute inflammatory triggers. Equally important in lung development is the anti-inflammatory cytokine and growth factor TGF- $\beta$, which is known to have a crucial role in vascular and alveolar development (29). Here, we found a decrease of TGF- $\beta$ mRNA after chronic and acute inflammation, which parallels our findings on disturbed proliferation and differentiation in the alveoli.

Furthermore, prenatal changes in endothelial cells and fibroblast have been reported due to inflammation and subsequent preterm birth (15). Inflammation- and preterm birth-induced changes in signaling processes and epithelial cell pools point towards alterations in the delicate stem cell niches as a potential contributor to stem/progenitor cell loss (27). However, whether possible alterations in the niches are a cause or consequence of stem cell attenuation remains to be determined.

Another interesting theory is the concept of advanced aging of premature lungs. With respect to stem cells, one of the crucial aspects of aging is a diminished capacity of stem cells to renew and differentiate into other cell types (30). Interestingly, a decreased proliferation potential in alveoli and a reduced differentiation of AEC2 into AEC1 was detected in the current study after prenatal inflammation. Postnatally, aging-associated molecular pathway alterations were reported in neonatal lungs of BPD patients (31). Further in-depth investigation of molecular pathways, including epigenetic alterations, changes in chromatin 


\section{AUTHOR ACCEPTED MANUSCRIPT}

remodeling, and mitochondrial dysfunction are required to examine the association of developmental changes with advanced aging in preterm lungs (31).

The prenatal loss of stem/progenitor cells is considered to have functional consequences postnatally. This concept is supported by the obtained data, where we observed both aberrant cellular differentiation along with lower proliferation in alveoli.

Hereby, we show that intrauterine inflammation leads to an arrest in lung development already in utero, while disturbed alveolar development has so far been observed postnatally in BPD patients (32)

Interestingly, reduced progenitor function (lower proliferation and differentiation) was accompanied by changes in surfactant synthesis. Whether surfactant mRNA levels increased as compensatory reaction to AEC2 and AEC1 loss, or whether enhanced surfactant synthesis suppresses proliferation and differentiation potential of AEC2, remains to be investigated. The increased lung gas volumes after chronic UP exposure without changes in surfactant mRNA, indicate that other mechanisms required for lung development are involved in the apparent maturation of the preterm lungs during antenatal stress, as shown previously (33). Regardless, our data support the dogma that improved lung function occurs at the expense of maintaining appropriate lung development $(34,35)$. The observed inflammation-associated loss of stem/progenitor cells in utero may persist into postnatal development, and may contribute to adverse pulmonary outcomes.

Indeed, alterations in epithelial stem cell pools have been detected postnatally, and associated with subsequent changes in lung function. For instance, neonates dying from RDS showed reduced TTF-1 expression in distal and terminal bronchioles and in alveoli (11), which was associated with the incidence of pneumonia and pulmonary hemorrhage. Similar observations were published by Stahlman et al. confirming the reduced expression of TTF-1 in RDS (9). 


\section{AUTHOR ACCEPTED MANUSCRIPT}

Additionally, they reported lower expression of TTF-1 in BPD patients, particularly in regions of acute inflammation, hemorrhage and edema. In a postnatal hyperoxia mouse model, depletion of AEC2 and inhibition of their proliferative capacity was reported in newborn mice. These reduced AEC2 numbers were associated with disrupted development of alveoli, and persisted until mice were full-grown and led to increased susceptibility to severe respiratory viral infections $(36,37)$. Deptula et al. showed increased P63 expression and repair of injured airways by activated basal and Club cells, after excessive postnatal ventilation of preterm lambs for several hours (38). In contrast, reduced numbers but no apparent change in function were found in the current prenatal study after inflammation, suggesting that the timing of stimulation, the duration and type of trigger play a crucial role in the response of the lung tissue.

In this proof of concept study, we aimed to investigate whether endogenous stem/progenitor cells are affected by antenatal infection/inflammation. We indeed find concrete evidence that chronic and acute inflammation depleted stem/progenitor populations of different lung compartments. However, future studies are required to further substantiate on stem/progenitor cell level and therefore the use of multiple cell surface markers is essential. Consequently, by using immunohistochemical analyses we cannot determine specific stem or progenitor subsets that might be affected in the developing lungs. For this purpose, complimentary analysis on sorted cells (FACS) and single cell sequencing would be highly informative.

Furthermore, the response of stem/progenitor populations varies according to the type of trigger and duration of inflammation. To clarify the variation in response, effects that might have occurred between the $7 \mathrm{~d}$ and $42 \mathrm{~d}$ of exposure need to be assessed.

Investigating the specific type of stem/progenitor pool and underlying causes of the stem/progenitor cell loss will be of great importance for clinical applications to prevent or treat pre- and postnatal structural and functional changes before adverse lung outcomes can 


\section{AUTHOR ACCEPTED MANUSCRIPT}

occur. Among others, reduced surfactant metabolism and simplified lung structures in prematurely born infants are already being addressed in the clinics. For instance, corticosteroids are administered when extreme preterm birth is expected (39), to enhance lung maturation, facilitating breathing after preterm delivery. Infants also receive exogenous surfactant treatment to improve lung compliance (40). Nevertheless, intrauterine inflammation-induced delay of lung development, predisposing the already immature preterm lungs to chronic lung diseases like BPD and asthma, remains untreated. Our data indicate that altered epithelial stem/progenitor pools and potentially impaired function start prenatally, so that the administration of therapies should be initiated even earlier than for instance corticosteroid treatment.

In summary, we report that chronic and acute intrauterine inflammation improve the function of the immature lungs but reduce endogenous epithelial stem/progenitor cells and their function, which might be a novel mechanistic explanation/link between the susceptibility of the lungs for further postnatal injury and prenatal inflammation. The data suggest that addressing developmental problems in the premature lungs as early as possible, will prevent exacerbation of structural changes and diminish the incidence of adverse pulmonary outcomes postnatally. 


\section{References}

1. Sabic, D., Koenig, J.M. A perfect storm: fetal inflammation and the developing immune system. Pediatr Res (2019).

2. Peng, C.C., et al. Intrauterine inflammation, infection, or both (Triple I): A new concept for chorioamnionitis. Pediatr Neonatol 59:231-237(2018).

3. Berger, A., et al. Microbial invasion of the amniotic cavity at birth is associated with adverse short-term outcome of preterm infants. J Perinat Med 31:115-121(2003).

4. Galinsky, R., et al. The consequences of chorioamnionitis: preterm birth and effects on development. J Pregnancy 2013:412831(2013).

5. Thomas, W., Speer, C.P. Chorioamnionitis is essential in the evolution of bronchopulmonary dysplasia--the case in favour. Paediatr Respir Rev 15:49-52(2014).

6. Alvira, C.M., Morty, R.E. Can We Understand the Pathobiology of Bronchopulmonary Dysplasia? J Pediatr 190:27-37(2017).

7. Möbius, M.A., Thébaud, B. Bronchopulmonary dysplasia: where have all the stem cells gone?: Origin and (Potential) function of resident lung stem cells. Chest 152:1043-1052(2017). 


\section{AUTHOR ACCEPTED MANUSCRIPT}

8. Collins, J.J., Thebaud, B. Progenitor cells of the distal lung and their potential role in neonatal lung disease. Birth Defects Res A Clin Mol Teratol 100:217-226(2014).

9. Stahlman, M.T., Gray, M.E., Whitsett, J.A. Expression of thyroid transcription factor1 (TTF-1) in fetal and neonatal human lung. Journal of Histochemistry \& Cytochemistry 44:673-678(1996).

10. Yee, M., et al. Alternative Progenitor Lineages Regenerate the Adult Lung Depleted of Alveolar Epithelial Type 2 Cells. Am J Respir Cell Mol Biol 56:453-464(2017).

11. Das, I., et al. A study of spectrum of pulmonary pathology and expression of thyroid transcription factor-1 during neonatal period. Indian J Pathol Microbiol 61:334$338(2018)$

12. Willems, M.G., et al. Pulmonary vascular changes in extremely preterm sheep after intra-amniotic exposure to Ureaplasma parvum and lipopolysaccharide. PloS one 12:e0180114(2017).

13. Kuypers, E., et al. Altered canonical Wingless-Int signaling in the ovine fetal lung after exposure to intra-amniotic lipopolysaccharide and antenatal betamethasone. Pediatr Res 75:281-287(2014).

14. Gussenhoven, R., et al. The Paradoxical Effects of Chronic Intra-Amniotic Ureaplasma parvum Exposure on Ovine Fetal Brain Development. Dev Neurosci 39:472-486(2017).

15. Willems, M.G., et al. Systemic interleukin-2 administration improves lung function and modulates chorioamnionitis-induced pulmonary inflammation in the ovine fetus. Am J Physiol Lung Cell Mol Physiol 310:L1-7(2016).

16. Leibel, S., Post, M. Endogenous and exogenous stem/progenitor cells in the lung and their role in the pathogenesis and treatment of pediatric lung disease. Frontiers in Pediatrics 4:36(2016). 


\section{AUTHOR ACCEPTED MANUSCRIPT}

17. Peake, J.L., Pinkerton, K.E. 2015 Gross and subgross anatomy of lungs, pleura, connective tissue septa, distal airways, and structural units. Comparative biology of the normal lung. Elsevier, pp 21-31.

18. Vaughan, A.E., et al. Lineage-negative progenitors mobilize to regenerate lung epithelium after major injury. Nature 517:621-625(2015).

19. Danopoulos, S., et al. Human lung branching morphogenesis is orchestrated by the spatiotemporal distribution of ACTA2, SOX2, and SOX9. Am J Physiol Lung Cell Mol Physiol 314:L144-L149(2018).

20. Bianco-Miotto, T., et al. Epigenetics and DOHaD: from basics to birth and beyond. $J$ Dev Orig Health Dis 8:513-519(2017).

21. Postma, D.S., Bush, A., van den Berge, M. Risk factors and early origins of chronic obstructive pulmonary disease. Lancet 385:899-909(2015).

22. Um-Bergstrom, P., et al. Pulmonary outcomes in adults with a history of Bronchopulmonary Dysplasia differ from patients with asthma. Respir Res 20:102(2019).

23. Borghesi, A., et al. Circulating endothelial progenitor cells in preterm infants with bronchopulmonary dysplasia. Am J Respir Crit Care Med 180:540-546(2009).

24. Schittny, J.C. Development of the lung. Cell Tissue Res 367:427-444(2017).

25. Rennard, S.I., et al. Airway epithelial cells: functional roles in airway disease. Am J Respir Crit Care Med 150:S27-30(1994).

26. Davies, D.E. Epithelial barrier function and immunity in asthma. Ann Am Thorac Soc 11 Suppl 5:S244-251(2014).

27. Donne, M.L., Lechner, A.J., Rock, J.R. Evidence for lung epithelial stem cell niches. BMC Dev Biol 15:32(2015). 


\section{AUTHOR ACCEPTED MANUSCRIPT}

28. Ota, C., et al. Linking bronchopulmonary dysplasia to adult chronic lung diseases: role of WNT signaling. Mol Cell Pediatr 3:34(2016).

29. Saito, A., Horie, M., Nagase, T. TGF-beta Signaling in Lung Health and Disease. Int J Mol Sci 19(2018).

30. Ahmed, A.S., et al. Effect of aging on stem cells. World J Exp Med 7:1-10(2017).

31. Meiners, S., Hilgendorff, A. Early injury of the neonatal lung contributes to premature lung aging: a hypothesis. Mol Cell Pediatr 3:24(2016).

32. Jobe, A.H., Bancalari, E. Bronchopulmonary dysplasia. Am J Respir Crit Care Med $163: 1723-1729(2001)$.

33. Viscardi, R., et al. Disordered pulmonary myofibroblast distribution and elastin expression in preterm infants with Ureaplasma urealyticum pneumonitis. Pediatr Dev Pathol 9:143-151(2006).

34. Choi, C.W., et al. Protective effect of chorioamnionitis on the development of bronchopulmonary dysplasia triggered by postnatal systemic inflammation in neonatal rats. Pediatr Res 79:287-294(2016).

35. Willet, K.E., et al. Antenatal endotoxin and glucocorticoid effects on lung morphometry in preterm lambs. Pediatr Res 48:782-788(2000).

36. Yee, M., Buczynski, B.W., O'Reilly, M.A. Neonatal hyperoxia stimulates the expansion of alveolar epithelial type II cells. Am J Respir Cell Mol Biol 50:757$766(2014)$

37. Yee, M., et al. Type II epithelial cells are critical target for hyperoxia-mediated impairment of postnatal lung development. Am J Physiol Lung Cell Mol Physiol 291:L1101-1111(2006). 


\section{AUTHOR ACCEPTED MANUSCRIPT}

38. Deptula, N., et al. Brief mechanical ventilation causes differential epithelial repair along the airways of fetal, preterm lambs. Am J Physiol Lung Cell Mol Physiol 311:L412-420(2016).

39. Kemp, M., et al. The clinical use of corticosteroids in pregnancy. Hum Reprod Update 22:240-259(2015).

40. Curstedt, T., Halliday, H.L., Speer, C.P. A unique story in neonatal research: the development of a porcine surfactant. Neonatology 107:321-329(2015).

\section{Acknowledgments}

We would like to thank Nico Kloosterboer and Lilian Kessels for their excellent technical assistance. 


\section{Figure legends}

Figure 1. Acute inflammation caused an immune response in preterm lungs $2 \mathrm{~d}$ before delivery, characterized by cytokine/chemokine increases and immune cell infiltration. (A-D) Results for IL-6, IL-8, CCL2 and CCR2 are depicted as relative fold changes in mRNA levels against saline. (E-F) CD45+ cells and MPO+ neutrophils were counted in alveolar walls, alveolar airspaces and perivascular space and expressed as cells $/ \mathrm{mm}^{2}$ of alveolar tissue. $\mathrm{n}=6$ 9, per group. ${ }^{*} p<0.05, * * p<0.01, * * * p<0.001, * * * * p<0.0001$ vs. SAL.

Figure 2. Intra-amniotic LPS exposure reduces P63+ basal cells in the proximal airways, without changes in SOX-2 and KRT-14. (A) SOX-2 mRNA levels are shown as relative fold changes against saline. (B-C) P63+ and KRT-14+ basal cells are presented as cells/mm of the broncho-epithelial lining of proximal airways. Representative images for P63 (indicated by 


\section{AUTHOR ACCEPTED MANUSCRIPT}

arrows) are displayed for saline (D), 42d UP (E), 2d (F) and 7d LPS (G) groups. Image magnification is $200 \mathrm{x}\left(1000 \mathrm{x}\right.$ for insert), scale bar is $100 \mu \mathrm{m} . \mathrm{n}=6-9$, per group. ${ }^{*} p<0.05$ vs. SAL.

Figure 3. Intra-amniotic exposure to UP or LPS decreases mRNA levels of transcription factor SOX-9 and reduces the progenitor pool of Club cells in distal bronchioles. (A) SOX-2 mRNA levels are depicted as relative fold changes against saline. (B) TTF-1+ Club cells were counted and correct for length of bronchiolar lining in distal airways. Representative images for Club cells (indicated by arrows) are shown for saline (C), 42d UP-exposed (D), $2 \mathrm{~d}(\mathbf{E})$ and 7d LPS-exposed animals (F). Image magnification is 200x (1000x for insert), scale bar is $100 \mu \mathrm{m} . \mathrm{n}=6-9$, per group. ${ }^{*} p<0.05, * * p<0.01$ vs. SAL.

Figure 4. Intra-amniotic exposure to UP or LPS reduces potential alveolar progenitor cell populations, proliferation, TGF- $\beta$ and Aqp5 expression. (A, C) TTF-1+ AEC2 and Ki67+ cells were enumerated in alveolar walls and are shown as cells $/ \mathrm{mm}^{2}$ of alveolar tissue. Representative images for AEC2 (indicated by arrows) are shown for saline (E), 42d UP (F), 2d LPS (G) and 7d LPS animals (H). Image magnification is 200x (1000x for insert), scale bar is $100 \mu \mathrm{m}$. (B, D) TGF- $\beta$ and Aqp5 mRNA levels are shown as relative fold changes against saline. $\mathrm{n}=6-9$, per group. ${ }^{*} p<0.05,{ }^{*} p<0.01$ vs. SAL.

Figure 5. Acute LPS exposure affects mRNA levels of surfactant proteins A-D in preterm ovine lungs, while lung gas volumes are increased by chronic and acute inflammatory stimuli. (A-D) SP A-D mRNA levels are displayed as relative fold changes against saline. (E) Lung gas volumes were normalized to fetal body weight as $\mathrm{ml} / \mathrm{kg}$. $\mathrm{n}=6-9$, per group. ${ }^{*} p<0.05$, $* * p<0.01, * * * p<0.001$ vs. SAL. 
Table 1. Primer sets used for real-time PCR

\begin{tabular}{|c|c|c|}
\hline GENE & & SEQUENCE (5'-3') \\
\hline TNF-A & $\begin{array}{l}\text { Fw } \\
\text { Rv }\end{array}$ & $\begin{array}{l}\text { СCTCTCTCTAATCAGCCCTCTG } \\
\text { GAGGACCTGGGAGTAGATGAG }\end{array}$ \\
\hline CCL2 & $\begin{array}{l}\mathrm{Fw} \\
\mathrm{Rv}\end{array}$ & $\begin{array}{l}\text { CTCGCTGCAACATGAAGTTCTC } \\
\text { GGGAGTTAATTGCATCTGGCTG }\end{array}$ \\
\hline CCR2 & $\begin{array}{l}\mathrm{FW} \\
\mathrm{Rv}\end{array}$ & $\begin{array}{l}\text { ATCTACCGGACCGAGGAAGA } \\
\text { TTCGGCAGGGTTCACTGTAA }\end{array}$ \\
\hline TGF-B & $\begin{array}{l}\mathrm{Fw} \\
\mathrm{Rv}\end{array}$ & $\begin{array}{l}\text { AAAAGAACTGCTGTGTTCGTCA } \\
\text { GACCTTGCTGTACTGTGTGTCC }\end{array}$ \\
\hline SOX-2 & $\begin{array}{l}\mathrm{Fw} \\
\mathrm{Rv}\end{array}$ & $\begin{array}{l}\text { ACAACTCTATGACCAGCTCGC } \\
\text { GCCCTGCTGAGAATAGGACA }\end{array}$ \\
\hline SOX-9 & $\begin{array}{l}\mathrm{Fw} \\
\mathrm{Rv}\end{array}$ & $\begin{array}{l}\text { CTCTGGAGACTGCTGAACGAG } \\
\text { GCCGTTCTTCACCGACTTCC }\end{array}$ \\
\hline AQP5 & $\begin{array}{l}\mathrm{Fw} \\
\mathrm{Rv}\end{array}$ & $\begin{array}{l}\text { ATCTACTTCACGGGCTGCTC } \\
\text { GGATGGCCACACGATCACTC }\end{array}$ \\
\hline GAPDH & $\begin{array}{l}\mathrm{Fw} \\
\mathrm{Rv}\end{array}$ & $\begin{array}{l}\text { GGAAGCTCACTGGCATGGC } \\
\text { CCTGCTTCACCACCTTCTTG }\end{array}$ \\
\hline YWHAZ & $\begin{array}{l}\text { Fw } \\
\text { Rv }\end{array}$ & $\begin{array}{c}\text { TGAACTCCCCTGAGAAAGCC } \\
\text { TCCGATGTCCACAATGTCAAGT }\end{array}$ \\
\hline
\end{tabular}

ABBREVIATIONS: FW, FORWARD; RV, REVERSE;

CCL2, MONOCYTE CHEMOTRACTIC PROTEIN 1;

CCR2, CHEMOKINE RECEPTOR TYPE 2; TGF-B,

TRANSFORMING GROWTH FACTOR; SOX-2, -9, SRY-

RELATED HMG-BOX-2, -9; AQP5, AQUAPORIN 5;

GAPDH, GLYCERALDEHYDE 3-PHOSPHATE

DEHYDROGENASE; YWHAZ, HUMAN 14-3-3

PROTEIN ZETA/DELTA 

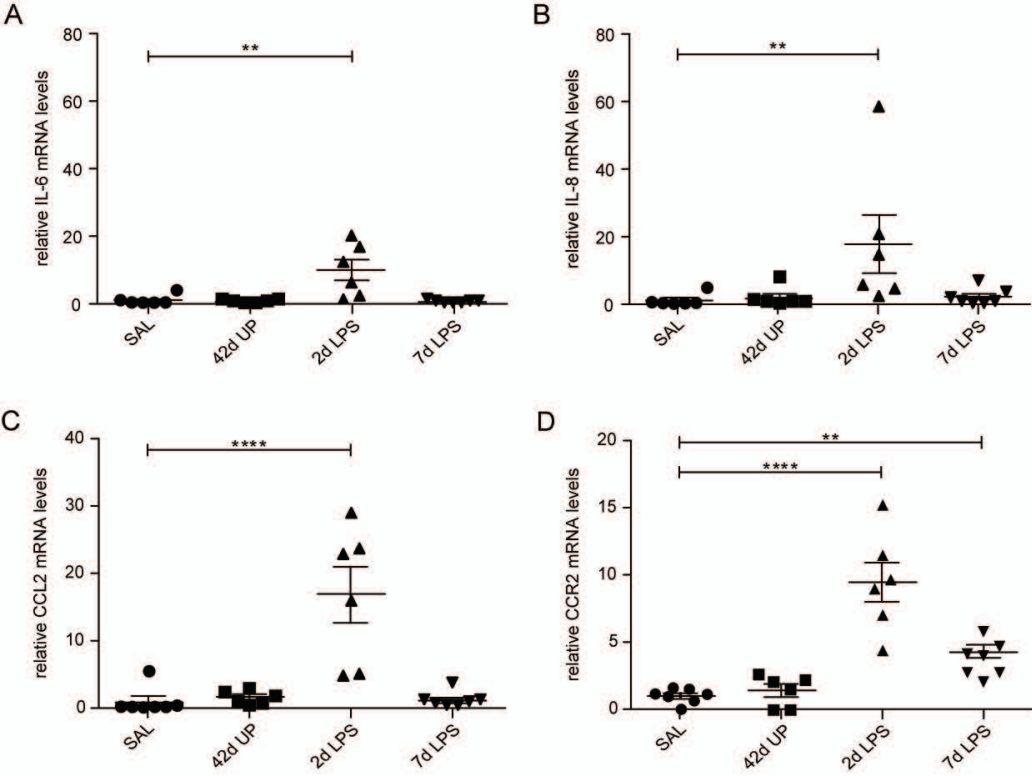

D

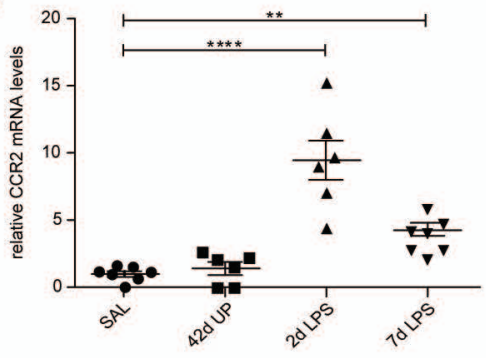

$E$

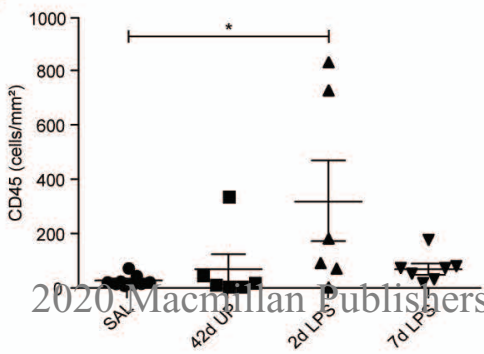

F

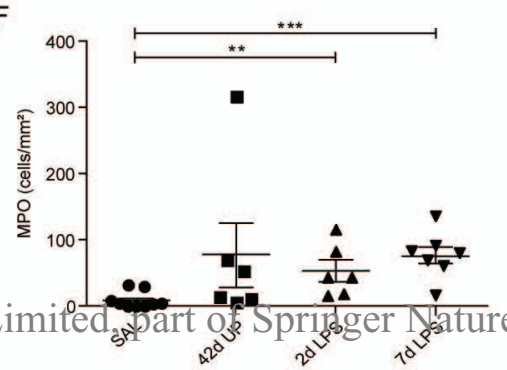


A

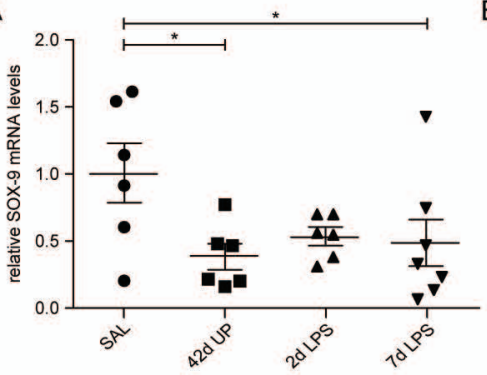

C

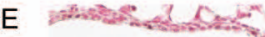

$$
\lambda
$$

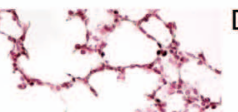

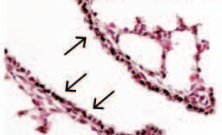

trats
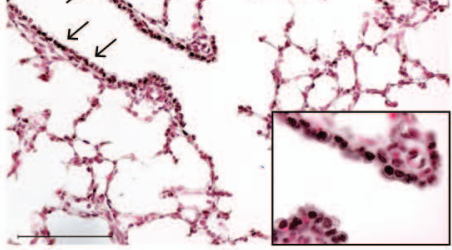

B

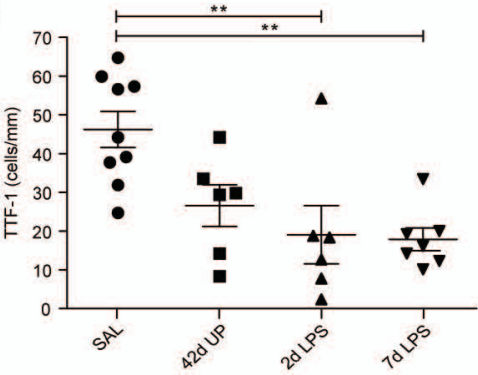

D

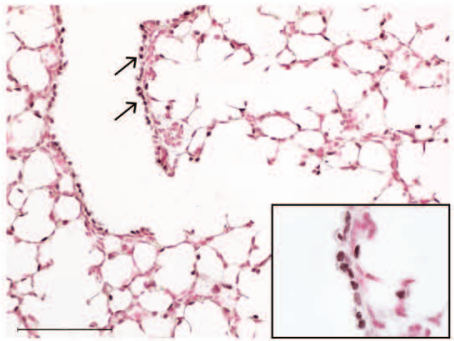
de flu

tot (1) है

$2020 \mathrm{~A}$ acto

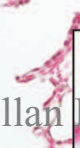

Publishers 

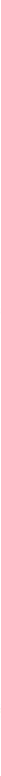

E

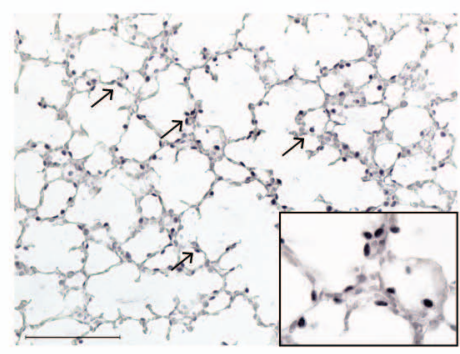

F

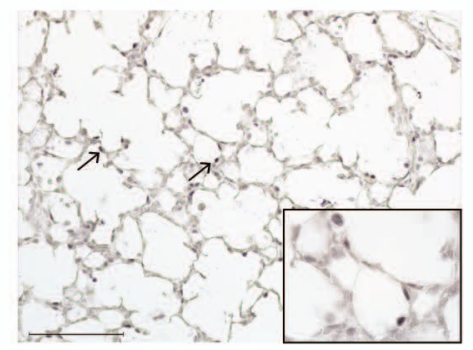

G

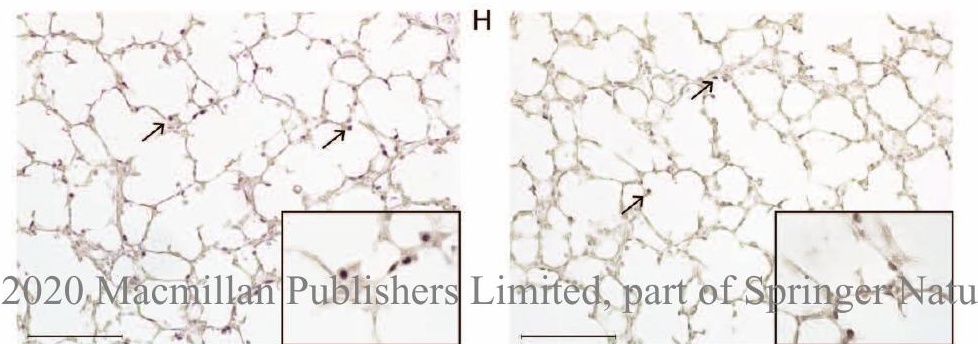



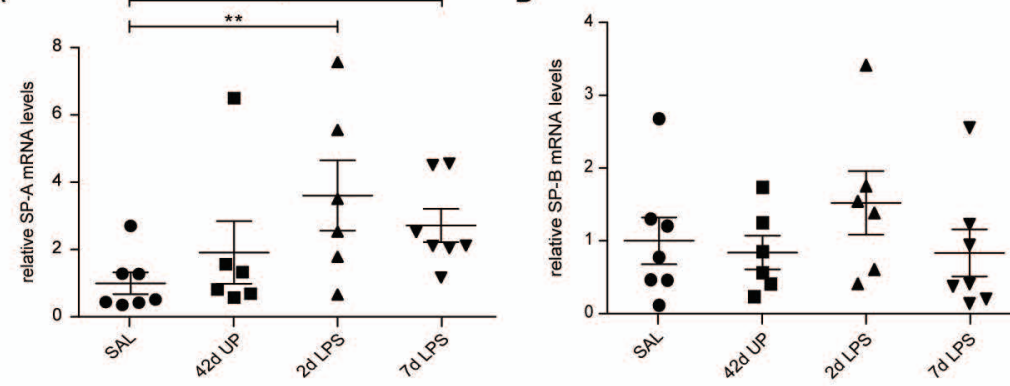

C
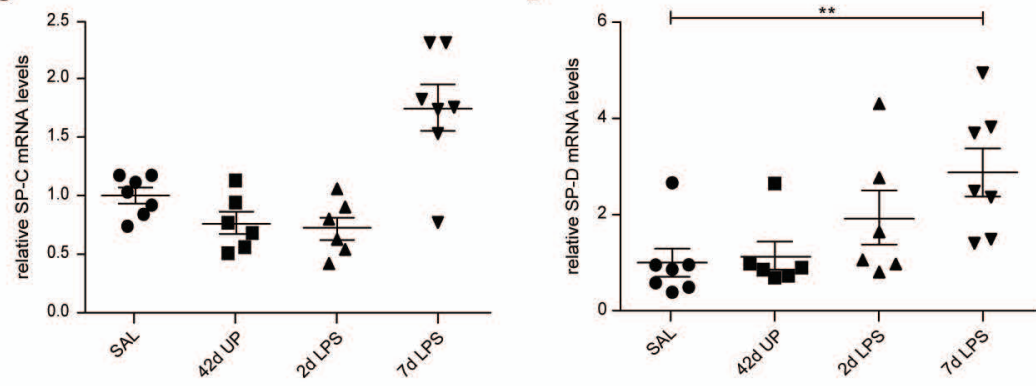

E

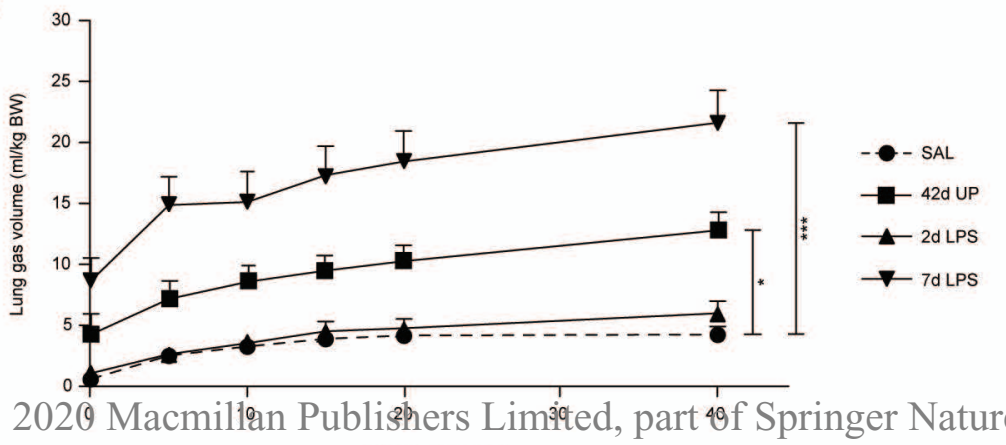

Pressure $\left(\mathrm{cmH}_{2} \mathrm{O}\right)$ 